" natural history" of the disease, which must run its course under controlled conditions. After this, the best result was achieved in most cases by bony ankylosis, and the best method was that of ischio-femoral arthrodesis as described by Brittain. In their anxiety to master the local disease they had perhaps taken too light a view of the disability inseparable from stiffness. Therefore operations providing complete excision when the disease was quiescent deserved serious consideration: nevertheless reports of success were very few at present. Mr. Seddon dwelt upon some of the ill effects of conservative treatment, particularly those due to defective epiphysial growth in the region of the knee on the affected side. He mentioned also the problem of general skeletal decalcification, the effects of which could be minimized by mobilizing the patient with his retaining apparatus. Treatment with streptomycin was uncertain, but it was certain that with it there was a prospect of arresting the disease quickly, and therefore it was a matter of great urgency that tuberculous hip disease be recognized early so that such treatment could be given before the pathological changes had become irreversible.

Mr. R. S. GARDEN (Preston) gave an account of the early symptoms and signs of the disease, especially in children, who comprised $80 \%$ of cases. Pain and limp representing hypersensitivity of the joint might be the only features. The main point was that there was no characteristic sign and that all such cases demanded careful observation. Mr. Dillwyn Evans (Cardiff), discussing conservative treatment, emphasized the need to understand the disease as a whole, since it affected the patient as a whole-socially and psychologically as well as physically. Treatment of the affected joint must not be an isolated circumstance; at the same time the surgeon must see to it that the patient did not suffer from deleterious sequelae which might be the result of treatment. The surgeon's role had been largely that of a passive spectator of the evolution of the disease under, it was true, the controlied conditions of rest and good hygiene. Now there were the gratifying possibilities (he could say no more at the moment) in the use of streptomycin. Mr. Evans reported upon 80 cases (not a'l disease of the hip-joint) thus treated, in none of which had streptomycin resistance been found; very few toxic effects were observed with the dosage of $1 \mathrm{~g}$. daily for 90 days. The best results appeared to be in early cases, and this again showed the need for early diagnosis, for which, Mr. Evans said, much more frequent use should be made in doubtful cases of joint biopsy. Mr. E. N. WARDLE (Liverpool) noted that the aim of surgery should be to hasten the production of bony ankylosis. In children he believed that ileo-femoral arthrodesis with iliac grafting was the best method, because it was relatively simple and safe and there was less risk of complications.

\section{Results of Trea'ment}

Mr. J. DoBson (Wrightington) aralysed the re-ul's of treatment based upon a study of 320 patients with tuberculosis of the hip-joint. Forty-six per cent of patients were under 10 years of age. No proved case of infection by the bovine bacillus was discovered among those studied bacteriologically ; at least $22 \%$ had a clear history of family contact with pulmonary tuberculosis. Twenty-one per cent of patients had multiple lesions (in other joints or sys'ems)-above the age of 20 the percentage was 43. Premature fusion of knee epiphyses occurred in not less than $23 \%$ of patients under 15 years of age. In the complete series $79 \%$ were discharged from hospital as quiescent. The mortality rate was $15 \%$, though the rate in patients with multiple lesions was $37 \%$. In chiloren $71 \%$ of the deaths were due to meningitis. At Wrighting:on the completion of conservative treatment by a fusion operation had not been done as a routine, but $\mathrm{Mr}$. Dobson was now convinced of its necessity in most cases if deformity or recurrence of the disease-complications which were frequent in cases having only fibrous ankylosis-was to be prevented. He believed that the Brittain ischio-femoral arthrodesis was the method of choice in children under 12 .

In the general discussion which followed, Mr. BRYAN MCFARLAND remarked upon the striking absence of bovine infection in Mr. Dobson's cases. He believed that osteotomy played an important part in altering the line of weight-bearing in the ischio-femoral arthrodesis, and he emphasized that surgeons were dealing with patients, not joints alone. Mr. G. F. Fisher (Liverpool and Johannesburg, South Africa) discussed ways and means of increasing the susceptibility of organisms to antibiotic drugs, in particular by "spreading " the influence of the drug through a wider area of tissue, and he mentioned the possibility, not yet proved, of achieving this by hyaluronidase or similar agents. Mr. NORMAN W. ROBERTS (Liverpool) believed that most hip-joint lesions were primarily synovial in origin, and that underlined the need for early diagnosis and treatment by streptomycin. Mr. H. OSMOND CLARKE (London) discussed the value of gland as well as joint biopsy as necessary aids to early diagnosis. Mr. SEDDON in his summing up stated that gland biopsy should first be done, but, if this was negative and the Mantoux test positive, then joint biopsy must be proceeded with. These examinations should be undertaken very early in the course of the disease.

\section{Preparations and Appliances}

\section{CONTROLLER FOR THE ALL-GLASS SYRINGE}

Dr. Hamish M. ManN, of Glasgow, writes: A free hand to manipulate the patient's skin is an advantage in the injection of local analgesics. One-handed control of the all-glass syringe can be inadequate, as the first and second fingers of the injecting hand have to provide an equal and opposite reaction to the force of the injecting thumb against the small flange at the head of the syringe, power being dissipated in opposing these fingers in addition to the essential effort of flexion.

A stainless steel, or nickel, controller (see illustration), consisting of three rings, the centre ring-in a plane at right-angles

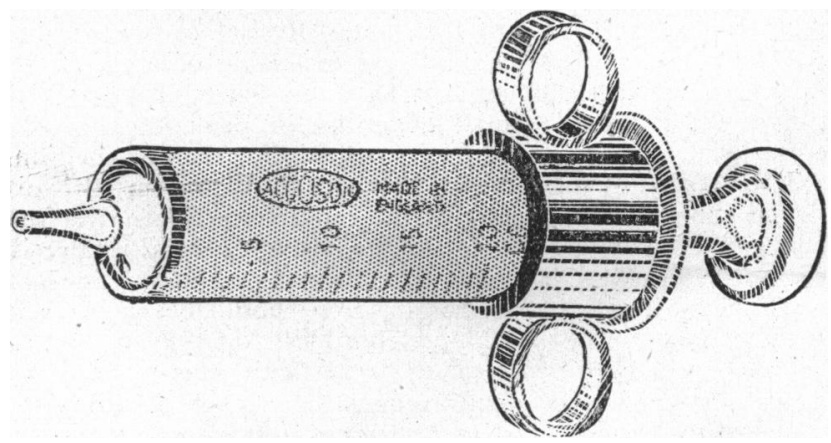

to the outer rings-being made to slide over the barrel and impinge on the flange of the syringe, has been devised, which gives better one-handed control and greater force of injection. It will fit all-glass syringes of the uniform outside diameter for which it is made-that is, in 5,10 , and $20 \mathrm{ml}$. sizes. The controller may be obtained from Messrs. Vicarey Davidson and Co., 162, Bath Street, Glasgow, C.2.

A similar device could be adapted to fit loosely the metalglass syringes in which the metal base and nozzle are wider than the glass barrel ; but, in view of M.R.C. War Memorandum, 1945 , No. 15 , on the care and sterilization of syringes, this has not been felt to be worth while.

I am indebted to. Mr. Stewart L. Mann for help and advice, and to Mr. Wilfrid Burley for making the prototype.

The Minister of Health has considered the rents charged for houses and flats now owned by him and occupied by hospital staff. A circular from the Ministry states that the rents charger to hospital staffs will in general be fixed by committees ar,d boards by reference to the rents normally charged for $\mathrm{cr}, \mathrm{m}$ parable properties in the neighbourhood. The hospital authority should seek the co-operation of the local housing authority in determining the appropriate rent. 